\title{
Magnetic compensation, field-dependent magnetization reversal, and complex magnetic ordering in $\mathrm{Co}_{2} \mathrm{TiO}_{4}$
}

\author{
S. Nayak, ${ }^{1}$ S. Thota,,${ }^{1,}$ D. C. Joshi, ${ }^{1}$ M. Krautz, ${ }^{2}$ A. Waske, ${ }^{2}$ A. Behler, ${ }^{2}$ J. Eckert,${ }^{3,4}$ T. Sarkar, ${ }^{5}$ M. S. Andersson, ${ }^{5}$ \\ R. Mathieu, ${ }^{5}$ V. Narang, ${ }^{6}$ and M. S. Seehra ${ }^{6, \dagger}$ \\ ${ }^{1}$ Department of Physics, Indian Institute of Technology Guwahati, Guwahati-781039, Assam, India \\ ${ }^{2}$ IFW Dresden, Institute for Complex Materials, P.O. Box 270116, D-01171 Dresden, Germany \\ ${ }^{3}$ Erich Schmid Institute of Materials Science, Austrian Academy of Sciences, Jahnstraße 12, A-8700 Leoben, Austria \\ ${ }^{4}$ Department Materials Physics, Montanuniversität Leoben, Jahnstraße 12, A-8700 Leoben, Austria \\ ${ }^{5}$ Department of Engineering Sciences, Uppsala University, Box 534, SE-751 21 Uppsala, Sweden \\ ${ }^{6}$ Department of Physics and Astronomy, West Virginia University, Morgantown, West Virginia 26506, USA
}

(Received 25 October 2015; published 23 December 2015)

\begin{abstract}
The complex nature of magnetic ordering in the spinel $\mathrm{Co}_{2} \mathrm{TiO}_{4}$ is investigated by analyzing the temperature and magnetic field dependence of its magnetization $(M)$, specific heat $\left(C_{\mathrm{p}}\right)$, and ac magnetic susceptibilities $\chi^{\prime}$ and $\chi^{\prime \prime}$. X-ray diffraction of the sample synthesized by the solid-state reaction route confirmed the spinel structure whereas $\mathrm{X}$-ray photoelectron spectroscopy shows its electronic structure to be $\mathrm{Co}_{2} \mathrm{TiO}_{4}=\left[\mathrm{Co}^{2+}\right]\left[\mathrm{Co}^{3+} \mathrm{Ti}^{3+}\right] \mathrm{O}_{4}$. From analysis of the temperature dependence of the dc paramagnetic susceptibility, the magnetic moments $\mu(A)=3.87 \mu_{\mathrm{B}}$ and $\mu(B)=5.19 \mu_{\mathrm{B}}$ on the $A$ and $B$ sites are determined with $\mu(B)$ in turn yielding $\mu\left(\mathrm{Ti}^{3+}\right)=$ $1.73 \mu_{\mathrm{B}}$ and $\mu\left(\mathrm{Co}^{3+}\right)=4.89 \mu_{\mathrm{B}}$. Analysis of the $\mathrm{dc}$ and ac susceptibilities combined with the weak anomalies observed in the $C_{\mathrm{p}}$ vs $T$ data shows the existence of a quasi-long-range ferrimagnetic state below $T_{\mathrm{N}} \sim 47.8 \mathrm{~K}$ and a compensation temperature $T_{\text {comp }} \sim 32 \mathrm{~K}$, the latter characterized by sign reversal of magnetization with its magnitude depending on the applied magnetic field and the cooling protocol. Analysis of the temperature dependence of $M$ (field cooled) and $M$ (zero field cooled) data and the hysteresis loop parameters is interpreted in terms of large spin clusters. These results in $\mathrm{Co}_{2} \mathrm{TiO}_{4}$, significantly different from those reported recently in isostructural $\mathrm{Co}_{2} \mathrm{SnO}_{4}=\left[\mathrm{Co}^{2+}\right]\left[\mathrm{Co}^{2+} \mathrm{Sn}^{4+}\right] \mathrm{O}_{4}$, warrant further investigations of its magnetic structure using neutron diffraction.
\end{abstract}

DOI: 10.1103/PhysRevB.92.214434 PACS number(s): 75.10.Nr, 75.20.-g, 75.30.Gw, 75.40.Gb

\section{INTRODUCTION}

Magnetic spinels are a remarkable class of materials, not only for their many applications, but also because of a wealth of new physics that continues to emerge from their fundamental investigations [1-6]. These properties result from many variations of the magnetic and nonmagnetic ions that can be accommodated on the tetrahedral $A$ sites and the octahedral $B$ sites in the $A B_{2} \mathrm{O}_{4}$ spinel structure, thus affecting the magnitudes of the superexchange interactions $J_{A A}, J_{B B}$, and $J_{A B}$ [7-9]. The presence of nonmagnetic ions on either the $A$ or the $B$ sites can lead to magnetic frustration [10-12]. For example, for normal spinels like $\mathrm{ZnFe}_{2} \mathrm{O}_{4}=\left[\mathrm{Zn}^{2+}\right]\left[\mathrm{Fe}_{2}^{3+}\right] \mathrm{O}_{4}^{4}$ and $\mathrm{MgMnO}_{3}=(3 / 4)\left\{\mathrm{Mg}^{2+}\right\}$ $\left[\left[\mathrm{Mg}^{2+}{ }_{1 / 3} \mathrm{Mn}^{4+}{ }_{4 / 3} \square_{1 / 3}\right] \mathrm{O}_{4}\right]$ [13], which have magnetic ions only on the $B$ sites with ' $\square$ ' as vacancy, the magnetic ground state is highly frustrated, as first predicted by Anderson in such a case [14].

We have recently reported on the nature of magnetic ordering in the spinel $\mathrm{Co}_{2} \mathrm{SnO}_{4}[15,16]$, for which the distributions of the ions on the $A$ and the $B$ sites was established to be $\left[\mathrm{Co}^{2+}\right]_{A}\left[\mathrm{Co}^{2+} \mathrm{Sn}^{4+}\right]_{B} \mathrm{O}_{4}$ by X-ray photoelectron spectroscopy (XPS). Analysis of the temperature dependence of both the ac and dc magnetic susceptibilities and specific heat measurements showed that $\mathrm{Co}_{2} \mathrm{SnO}_{4}$ is a ferrimagnet due to

\footnotetext{
*subhasht@iitg.ac.in

†mseehra@wvu.edu
}

slightly different magnetic moments of $\mathrm{Co}^{2+}$ on the $A$ and the $B$ sites below $41 \mathrm{~K}$, with some dynamical properties $[15,16]$.

$\mathrm{Co}_{2} \mathrm{TiO}_{4}$ is isostructural to $\mathrm{Co}_{2} \mathrm{SnO}_{4}$ in which $\mathrm{Sn}$ is replaced by $\mathrm{Ti}$ in the former. Although a number of papers have previously reported on the nature of magnetism in $\mathrm{Co}_{2} \mathrm{TiO}_{4}$, the results have been controversial. The magnetic studies of Hubsch and Gavoille [17] and Gavoille et al. [18] reported ferrimagnetic ordering at $T_{\mathrm{N}} \sim 55 \mathrm{~K}$ followed by spin-glass transition at $T_{\mathrm{SG}} \sim 46 \mathrm{~K}$. However, later ac susceptibility studies by Srivastava et al. [19], showed no indication of $T_{\mathrm{N}} \sim 55 \mathrm{~K}$, rather only a single peak in $\chi_{\text {ac }}$ near $48 \mathrm{~K}$ when $H_{\mathrm{dc}}=0$. In the studies of the temperature dependence of specific heat $C_{\mathrm{p}}$ of $\mathrm{Co}_{2} \mathrm{TiO}_{4}$ by Ogawa and Waki [20], only a weak peak in $C_{\mathrm{p}}$ vs $T$ was reported near $49 \mathrm{~K}$, which was associated with magnetic ordering, again signaling the absence of a transition near $55 \mathrm{~K}$. The magnetic studies by Hubsch and Gavoille also showed a magnetic compensation point near $30 \mathrm{~K}$ [17]. In all these reported studies, it has been assumed that the electronic state of $\mathrm{Ti}$ in $\mathrm{Co}_{2} \mathrm{TiO}_{4}$ is $\mathrm{Ti}^{4+}$, similar to $\mathrm{Sn}^{4+}$ in $\mathrm{Co}_{2} \mathrm{SnO}_{4}$.

In this paper, we revisit the nature of magnetic ordering in $\mathrm{Co}_{2} \mathrm{TiO}_{4}$ in order to address the unsettled issues listed above and to examine the similarities and differences in the magnetic properties of $\mathrm{Co}_{2} \mathrm{TiO}_{4}$ and $\mathrm{Co}_{2} \mathrm{SnO}_{4}$. For example, why the compensation point observed in $\mathrm{Co}_{2} \mathrm{TiO}_{4}$ near $30 \mathrm{~K}$ [17] is not observed in $\mathrm{Co}_{2} \mathrm{SnO}_{4}$ [16] if the electronic states of $\mathrm{Co}$ in the two systems are similar. In our investigations of $\mathrm{Co}_{2} \mathrm{TiO}_{4}$, we have employed x-ray diffraction (XRD), XPS, temperature and magnetic field dependence of the ac and 
dc magnetic susceptibilities, and temperature and magnetic field dependence of specific heat measurements to unravel the nature of magnetic ordering in this system. From these studies, it is shown that the electronic state of $\mathrm{Ti}$ in $\mathrm{Co}_{2} \mathrm{TiO}_{4}$ is not $\mathrm{Ti}^{4+}$ but primarily $\mathrm{Ti}^{3+}$, resulting in the configuration $\left[\mathrm{Co}^{2+}\right]\left[\mathrm{Co}^{3+} \mathrm{Ti}^{3+}\right] \mathrm{O}_{4}$. In contrast to the case of $\mathrm{Co}_{2} \mathrm{SnO}_{4}$, this gives very different magnetic moments on the $A$ and the $B$ sites in $\mathrm{Co}_{2} \mathrm{TiO}_{4}$, which are also confirmed from the analysis of the temperature dependence of the paramagnetic susceptibility. It is argued that these distinctly different magnetic moments on the $A$ and the $B$ sites lead to the observed magnetic compensation near $30 \mathrm{~K}$. Also, our studies rule out any magnetic transition near $55 \mathrm{~K}$; instead, a transition to a quasi-long-range ferrimagnetic state akin to that of $\mathrm{Co}_{2} \mathrm{SnO}_{4}$ $[15,16]$ is found below $48 \mathrm{~K}$. Some new results in $\mathrm{Co}_{2} \mathrm{SnO}_{4}$ are also presented for comparison with $\mathrm{Co}_{2} \mathrm{TiO}_{4}$. Details of these results determined from multitechnique investigations and their discussion and analysis are presented below.

\section{EXPERIMENTAL PROCEDURES}

The bulk grain size polycrystalline $\mathrm{Co}_{2} \mathrm{TiO}_{4}$ and $\mathrm{Co}_{2} \mathrm{SnO}_{4}$ samples were synthesized by the standard solid-state reaction method starting with stoichiometric amounts of $\mathrm{Co}_{3} \mathrm{O}_{4}, \mathrm{TiO}_{2}$, and $\mathrm{SnO}_{2}$ as precursors. Appropriate amounts of these materials were first ground in an agate mortar and sieved through a 240 mesh. The mixed powders were pressed into pellets of diameter $\sim 13 \mathrm{~mm}$ using a hydraulic press with a maximum load of $5 \mathrm{ton} / \mathrm{cm}^{2}$. The pellets of $\mathrm{Co}_{2} \mathrm{TiO}_{4}$ were finally sintered at $1120^{\circ} \mathrm{C}\left(1350{ }^{\circ} \mathrm{C}\right.$ for $\mathrm{Co}_{2} \mathrm{SnO}_{4}$ [16] $)$ for $18 \mathrm{~h}$ in air to yield the desired compound without any impurities or unreacted precursors. The structural characterization was performed using a Rigaku x-ray diffractometer (model TTRAX III) with $\mathrm{Cu} \mathrm{K} \alpha$ radiation $(\lambda=1.54056 \AA$ ) followed by Rietveld refinement of the diffraction patterns using the FullProf program, which confirmed the phase purity of the samples (Fig. 1). Both dc magnetization and frequency dependence $(0.17-1.2 \mathrm{kHz})$ of ac magnetic susceptibility measurements were performed using a superconducting quantum interference device (SQUID) based magnetometer from Quantum Design with temperature capabilities of $2-320 \mathrm{~K}$ and magnetic field (H) up to $\pm 90 \mathrm{kOe}$. The low-temperature heat capacity data $\left[C_{\mathrm{p}}(T)\right]$ was recorded by means of a physical property measurement system (PPMS) from Quantum Design. The surface chemical composition of both the bulk samples were analyzed by means of XPS measurements performed with a dual source VG Microtech XPS microprobe system using $\mathrm{Al} \mathrm{K} \alpha$ radiation $(1486.8 \mathrm{eV})$ source at a base pressure of $8 \times 10^{-10}$ Torr. The XPS data were collected from 0 to $1100 \mathrm{eV}$ of binding energy (B.E.) which is acquired with constant pass energy of $100 \mathrm{eV}$. All the spectra were analyzed using Gaussian-Lorentzian curve fitting.

\section{STRUCTURAL AND ELECTRONIC CHARACTERIZATION}

\section{A. X-ray diffraction}

Figure 1 shows the XRD pattern of the polycrystalline samples of both $\mathrm{Co}_{2} \mathrm{TiO}_{4}$ and $\mathrm{Co}_{2} \mathrm{SnO}_{4}$ along with their Rietveld refinement done using the FullProf program. These

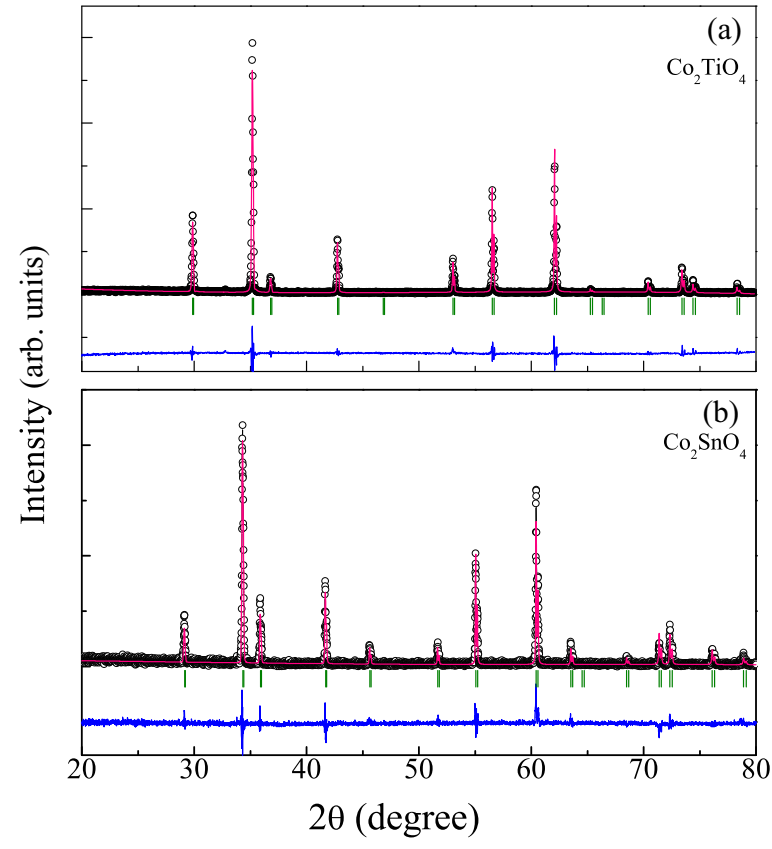

FIG. 1. (Color online) XRD patterns together with the Rietveld refined data of (a) $\mathrm{Co}_{2} \mathrm{TiO}_{4}$ and (b) $\mathrm{Co}_{2} \mathrm{SnO}_{4}$. The blue lines at the bottom represent difference between the measured and simulated patterns.

patterns are consistent with the standard cubic spinel phase with space group $F d-3 m$ (227). However, the lattice parameter obtained for $\mathrm{Co}_{2} \mathrm{TiO}_{4}(a=8.45 \AA)$ is slightly less than that of $\mathrm{Co}_{2} \mathrm{SnO}_{4}(a=8.66 \AA)$. Such variation in the lattice parameters is generally associated with the different ionic radii of the constituent elements. Since the ionic radius of tetravalent stannous ion $\left(\mathrm{Sn}^{4+}=0.69 \AA\right)$ is slightly greater than that of the titanium ion (either $\mathrm{Ti}^{4+}=0.605 \AA$ or $\mathrm{Ti}^{3+}=0.67 \AA$ ), larger unit cell dimensions of $\mathrm{Co}_{2} \mathrm{SnO}_{4}$ as compared to that of $\mathrm{Co}_{2} \mathrm{TiO}_{4}$ are expected. On the other hand, the ionic radius of $\mathrm{Co}^{2+}$ ions in tetrahedral sites with coordination number four is smaller $\left(\mathrm{Co}_{\text {Tetra-A }}^{2+}=0.58 \AA\right)$ than that in high spin octahedral sites with coordination number six $\left(\mathrm{Co}_{\text {Octa-B }}^{2+}=0.745 \AA\right)$. Table I summarizes the bond lengths and bond angles in both $\mathrm{Co}_{2} \mathrm{TiO}_{4}$ and $\mathrm{Co}_{2} \mathrm{SnO}_{4}$ estimated from the refinement process. It is evident that the average bond length $(B-\mathrm{O})$ between the oxygen ion and elements present in the octahedral sites of $\mathrm{Co}_{2} \mathrm{SnO}_{4}$ is higher than that in $\mathrm{Co}_{2} \mathrm{TiO}_{4}$, while the reverse is true for the tetrahedral sites. Such differences in bond lengths at the octahedral and tetrahedral sites in the two systems result from the difference in the ionic sizes. Since the $\mathrm{Sn}$ ion is larger than the Ti ions, the $B-\mathrm{O}$ bond length in $\mathrm{Co}_{2} \mathrm{SnO}_{4}$ is greater than that in $\mathrm{Co}_{2} \mathrm{TiO}_{4}$, resulting in a larger lattice parameter of $\mathrm{Co}_{2} \mathrm{SnO}_{4}$ than that of $\mathrm{Co}_{2} \mathrm{TiO}_{4}$ as observed experimentally.

\section{B. X-ray photoelectron spectroscopy}

For a detailed understanding of the electronic state of elements present in both systems, XPS measurements with $\mathrm{Al}-\mathrm{K} \alpha \mathrm{x}$-rays as source were performed. Figure 2 shows the intensity of XPS spectra vs binding energy of the Co- $2 p$ core levels for pure $\mathrm{Co}_{3} \mathrm{O}_{4}, \mathrm{Co}_{2} \mathrm{TiO}_{4}$, and $\mathrm{Co}_{2} \mathrm{SnO}_{4}$ systems. All these spectra exhibit two sharp peaks characteristic of 
TABLE I. The list of lattice parameters $(a=b=c)$, bond lengths, and bond angles in $\mathrm{Co}_{2} \mathrm{SnO}_{4}$ and $\mathrm{Co}_{2} \mathrm{TiO}_{4}$. ( $(\mathrm{The}$ interaxial angles $\left.\alpha=\beta=\gamma=90^{\circ}\right)$

\begin{tabular}{|c|c|c|c|c|c|}
\hline \multirow[b]{2}{*}{ System } & \multirow[b]{2}{*}{ Lattice parameter } & \multicolumn{2}{|c|}{ Bond length } & \multicolumn{2}{|c|}{ Bond angle } \\
\hline & & $A-\mathrm{O}$ & $B-\mathrm{O}$ & $A-\mathrm{O}-B$ & $B-O-B$ \\
\hline $\mathrm{Co}_{2} \mathrm{TiO}_{4}$ & $8.45 \pm 0.01 \AA$ & $1.98 \pm 0.011 \AA$ & $2.03 \pm 0.017 \AA$ & $121.68^{\circ} \pm 0.612^{\circ}$ & $94.95^{\circ} \pm 0.478^{\circ}$ \\
\hline $\mathrm{Co}_{2} \mathrm{SnO}_{4}$ & $8.66 \pm 0.02 \AA$ & $1.88 \pm 0.02 \AA$ & $2.16 \pm 0.021 \AA$ & $125.01^{\circ} \pm 0.625^{\circ}$ & $90.37^{\circ} \pm 0.452^{\circ}$ \\
\hline
\end{tabular}

$\mathrm{Co}-2 p_{3 / 2}$ and $\mathrm{Co}-2 p_{1 / 2}$ together with the weak intensity satellite peaks shown by arrows at $786.7 \mathrm{eV}\left(S_{1}\right)$ and $802.91 \mathrm{eV}$ $\left(S_{2}\right)$. It is well known that both $\mathrm{Co}^{2+}$ and $\mathrm{Co}^{3+}$ exhibit similar binding energy peaks in XPS data with a sharp transition near $780 \mathrm{eV}$ identified with $2 p_{3 / 2}$ level and a second peak near $796 \mathrm{eV}$ identified with $2 p_{1 / 2}$ level. However, the energy splitting $(\Delta E)$ between the two levels due to spin-orbit coupling should be different for the $\mathrm{Co}^{2+}$ and $\mathrm{Co}^{3+}$ configurations with $\Delta E=15.0 \mathrm{eV}$ for $\mathrm{Co}^{3+}$ and $\Delta E=15.7 \mathrm{eV}$ for $\mathrm{Co}^{2+}$ [21-23]. The XPS data in Fig. 2(a) for the spinel $\mathrm{Co}_{3} \mathrm{O}_{4}$, which contains both $\mathrm{Co}^{2+}$ and $\mathrm{Co}^{3+}$ ions distributed on the $A$ and the $B$ sites as $\left[\mathrm{Co}^{2+}\right]_{A}\left[2 \mathrm{Co}^{3+}\right]_{B} \mathrm{O}_{4}$, clearly show the presence of doublet at $D_{1}=779.84 \mathrm{eV}$ and $D_{2}=780.34 \mathrm{eV}$ for the Co- $2 p_{3 / 2}$ level and a doublet for the Co- $2 p_{1 / 2}$ level centered at $D_{3}=794.84 \mathrm{eV}$ and $D_{4}=796.09 \mathrm{eV}$. The separations between the doublet peaks are $\Delta E_{D_{1}-D_{3}}=15 \mathrm{eV}$ and $\Delta E_{D_{2}-D_{4}}=15.75 \mathrm{eV}$, which are close to the above-mentioned values for $\mathrm{Co}^{3+}$ and $\mathrm{Co}^{2+}$, respectively, thus confirming the

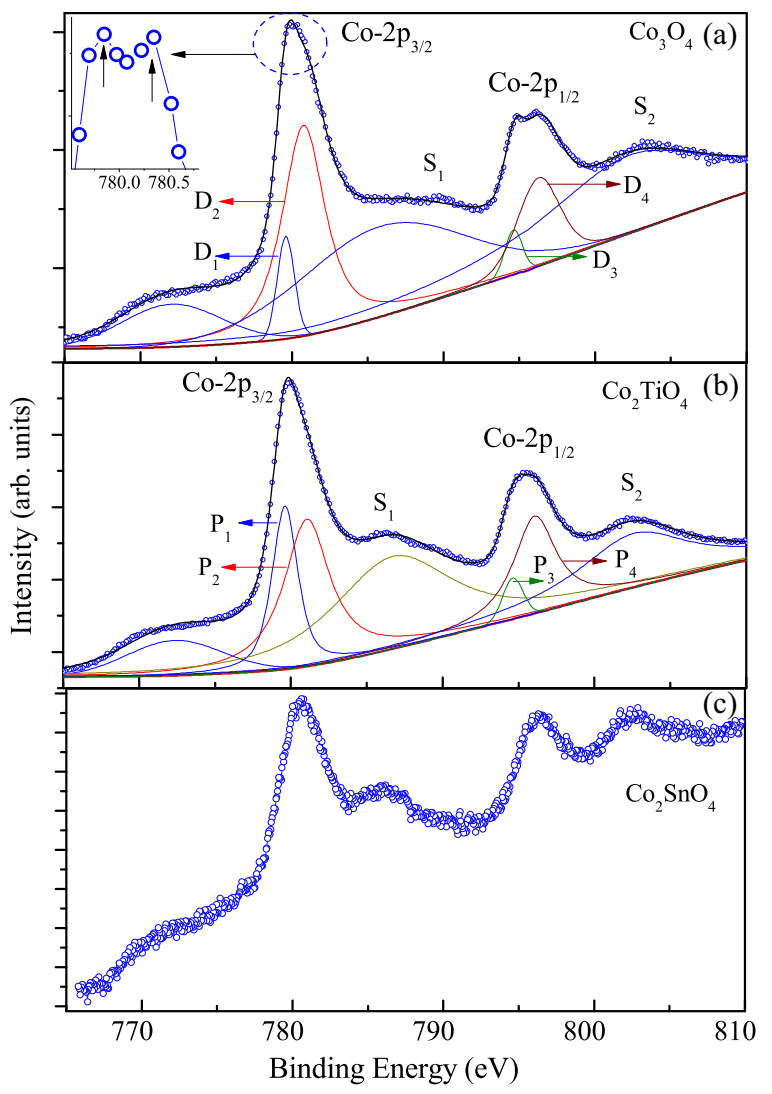

FIG. 2. (Color online) The XPS of $\mathrm{Co}-2 p$ peaks of (a) $\mathrm{Co}_{3} \mathrm{O}_{4}$, (b) $\mathrm{Co}_{2} \mathrm{TiO}_{4}$, and (c) $\mathrm{Co}_{2} \mathrm{SnO}_{4}$. presence of $\mathrm{Co}^{3+}$ and $\mathrm{Co}^{2+}$ in $\mathrm{Co}_{3} \mathrm{O}_{4}$. These results are in good agreement with the previously reported data by Chuang et al. [24].

Figure 2(b) shows the core level XPS spectra of Co- $2 p_{3 / 2}$ and $\mathrm{Co}-2 p_{1 / 2}$ for the spinel $\mathrm{Co}_{2} \mathrm{TiO}_{4}$. If the distribution of ions in $\mathrm{Co}_{2} \mathrm{TiO}_{4}$ is $\left[\mathrm{Co}^{2+}\right]\left[\mathrm{Co}^{2+} \mathrm{Ti}^{4+}\right] \mathrm{O}_{4}$, as has been assumed in previous studies, then this system should not exhibit any $\mathrm{Co}^{3+}$ character. However, our XPS studies in $\mathrm{Co}_{2} \mathrm{TiO}_{4}$ [Fig. 2(b)] show clear signatures of $\mathrm{Co}^{3+}$ state in addition to the $\mathrm{Co}^{2+}$ state in terms of doublets discussed above for $\mathrm{Co}_{3} \mathrm{O}_{4}$. For the XPS spectra of $\mathrm{Co}-2 p_{3 / 2}$ and $\mathrm{Co}-2 p_{1 / 2}$ levels, the simulated Gaussian-Lorentzian fitting yields two different intensity peaks with narrow separation labeled by $P_{1}$ and $P_{2}$ for $2 p_{3 / 2}$, and $P_{3}$ and $P_{4}$ for $2 p_{1 / 2}$, as shown in Fig. 2(b). The observed difference between the doublets $\Delta E_{P_{1}-P_{3}}=$ $14.98 \mathrm{eV}$ and $\Delta E_{P_{2}-P_{4}}=15.43 \mathrm{eV}$ provides the signatures of the $\mathrm{Co}^{3+}$ and $\mathrm{Co}^{2+}$, respectively, as compared to the expected values of $\Delta E=15.0 \mathrm{eV}$ for $\mathrm{Co}^{3+}$ and $\Delta E=15.7 \mathrm{eV}$ for $\mathrm{Co}^{2+}$ [16]. On the other hand, for the $\mathrm{Co}_{2} \mathrm{SnO}_{4}$ case, the data shown in Fig. 2(c) give, $\Delta E=15.7 \mathrm{eV}$ characteristic of $\mathrm{Co}^{2+}$ only, and no additional signatures for the $\mathrm{Co}^{3+}$ state are noticed in $\mathrm{Co}_{2} \mathrm{SnO}_{4}$, as also reported in our recent study [16].

Next, we consider the electronic states of $\mathrm{Ti}, \mathrm{Sn}$, and $\mathrm{O}$. For $\mathrm{TiO}_{2}$ with $\mathrm{Ti}^{4+}$ as the electronic state of titanium, the binding energy for the Ti-2 $p_{3 / 2}$ state is observed at $459.5 \mathrm{eV}$ [25]. However, in the case of $\mathrm{Co}_{2} \mathrm{TiO}_{4}$, the maximum intensity peak for Ti-2 $p_{3 / 2}$ appears at $457.65 \mathrm{eV}$ [Fig. 3(a)], while the second maximum intensity peak corresponding to Ti-2 $p_{1 / 2}$ is centered at $463.53 \mathrm{eV}$. This result rules out the presence of $\mathrm{Ti}^{4+}$ state in $\mathrm{Co}_{2} \mathrm{TiO}_{4}$. Instead, the observed position of the peak at $457.65 \mathrm{eV}$ agrees with the previously reported data of $\mathrm{Ti}^{3+}$ surface defects at $457.7 \mathrm{eV}$ in the $\mathrm{TiO}_{2}$ system [26]. In addition, these results also rule out the presence of any metallic Ti ions in the $\mathrm{Co}_{2} \mathrm{TiO}_{4}$ matrix, which usually show their signatures in XPS spectra at $454 \mathrm{eV}$. For $\mathrm{Co}_{2} \mathrm{SnO}_{4}$, the sharp peaks observed at 485.65 and $494.8 \mathrm{eV}$ and a weak shoulder at $496.75 \mathrm{eV}$ in Fig. 3(b) are the characteristic signatures of $\mathrm{Sn}^{4+}$ state [21,27]. Finally, Fig. 3(c) shows O-1s core level spectra for all the three systems with some signature of weakly bound surface oxygen at a binding energy close to $533 \mathrm{eV}$ [21-25,28,29]. The major conclusions from these comparative XPS studies in $\mathrm{Co}_{3} \mathrm{O}_{4}, \mathrm{Co}_{2} \mathrm{TiO}_{4}$, and $\mathrm{Co}_{2} \mathrm{SnO}_{4}$ are that, electronically, $\mathrm{Co}_{2} \mathrm{TiO}_{4}=\left[\mathrm{Co}^{2+}\right]\left[\mathrm{Co}^{3+} \mathrm{Ti}^{3+}\right] \mathrm{O}_{4}$, whereas $\mathrm{Co}_{2} \mathrm{SnO}_{4}=\left[\mathrm{Co}^{2+}\right]\left[\mathrm{Co}^{2+} \mathrm{Sn}^{4+}\right] \mathrm{O}_{4}$. This difference in the electronic state of Co ions on the $B$ sites of these two systems has never been reported before to our knowledge, and as we will show, it leads to major differences in the observed magnetic properties of $\mathrm{Co}_{2} \mathrm{TiO}_{4}$ from those of $\mathrm{Co}_{2} \mathrm{SnO}_{4}$. Below, we present detailed magnetic studies of $\mathrm{Co}_{2} \mathrm{TiO}_{4}$ 


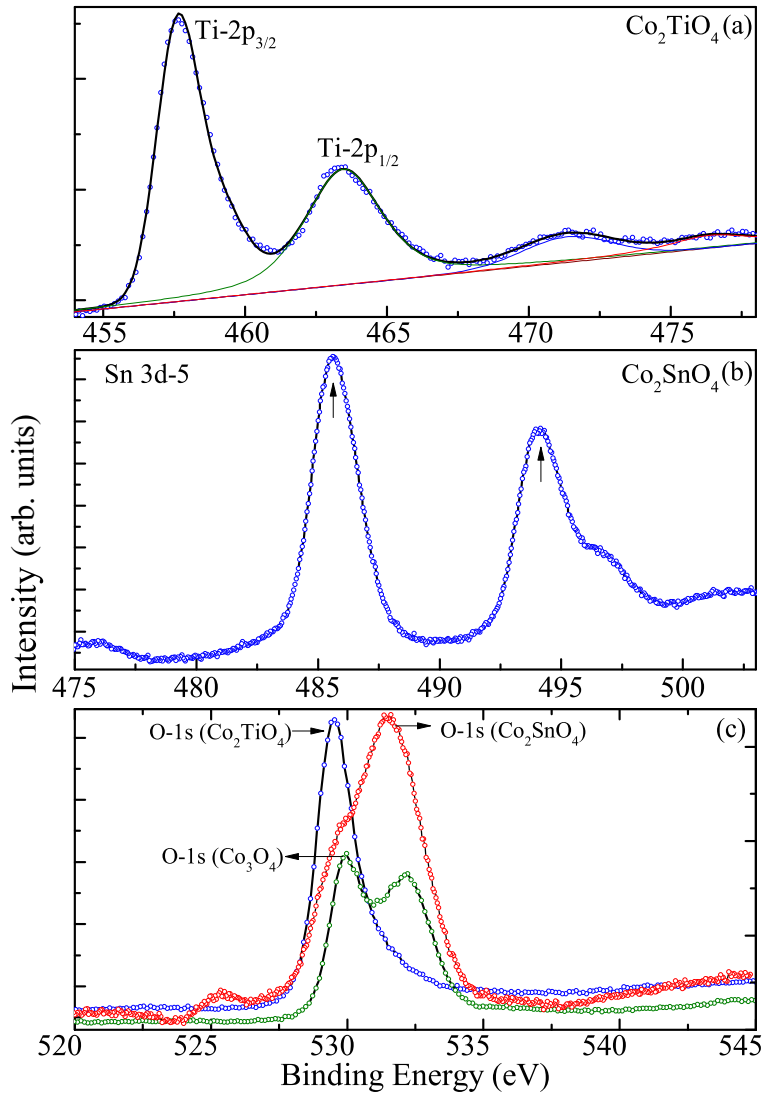

FIG. 3. (Color online) The XPS of (a) Ti-2 $p$, (b) $\mathrm{Sn}-3 d$, (c) $\mathrm{O}-1$ s peaks of $\mathrm{Co}_{2} \mathrm{TiO}_{4}, \mathrm{Co}_{2} \mathrm{SnO}_{4}$, and $\mathrm{Co}_{3} \mathrm{O}_{4}$ systems.

along with their discussion and interpretation, accompanied by comparison with $\mathrm{Co}_{2} \mathrm{SnO}_{4}$ where appropriate.

\section{RESULTS FROM MAGNETIC MEASUREMENTS}

\section{A. Temperature dependence of the paramagnetic susceptibility}

The temperature dependence of dc magnetic susceptibility ( $\chi$ ) of both $\mathrm{Co}_{2} \mathrm{TiO}_{4}$ and $\mathrm{Co}_{2} \mathrm{SnO}_{4}$ for $T>45 \mathrm{~K}$ recorded under zero field cooled (ZFC) conditions is shown in Fig. 4; here, $\chi^{-1}$ vs $T$ plots are shown with blue circles and green squares as experimental points and red and brown solid lines as fits to the Néel expression for ferrimagnets viz. $(1 / \chi)=(T / C)+$ $\left(1 / \chi_{0}\right)-\left[\sigma_{0} /(T-\theta)\right]$. The fit for $\mathrm{Co}_{2} \mathrm{TiO}_{4}$ yields the following parameters: $\chi_{0}=41.92 \times 10^{-3} \mathrm{emu} / \mathrm{mol}-\mathrm{Oe}, \sigma_{0}=31.55$ mol-Oe-K/emu, $C=5.245 \mathrm{emu} \mathrm{K} / \mathrm{mol} \mathrm{Oe}, \theta=49.85 \mathrm{~K}$. The ratio $C / \chi_{0}=T_{\mathrm{a}}=125.1 \mathrm{~K}$ represents the strength of the antiferromagnetic exchange coupling between the spins on the $A$ and $B$ sites and is often termed as the asymptotic Curie temperature $T_{\mathrm{a}}$. In Table II, various fitting parameters obtained from the Néel expression for ferrimagnetism of both $\mathrm{Co}_{2} \mathrm{TiO}_{4}$ and $\mathrm{Co}_{2} \mathrm{SnO}_{4}$ are summarized. The effective magnetic moment $\mu_{\text {eff }}=6.5 \mu_{\mathrm{B}}$ per formula unit (f.u.) of $\mathrm{Co}_{2} \mathrm{TiO}_{4}$ is determined using $C=N \mu_{\text {eff }}^{2} / 3 k_{\mathrm{B}}$. A similar calculation yielded $\mu_{\text {eff }}=6.25 \mu_{\mathrm{B}}$ per f.u. of $\mathrm{Co}_{2} \mathrm{SnO}_{4}=$ $\left[\mathrm{Co}^{2+}\right]\left[\mathrm{Co}^{2+} \mathrm{Sn}^{4+}\right] \mathrm{O}_{4}$. Using $\mu^{2}=[\mu(A)]^{2}+[\mu(B)]^{2}$ with $\mu(A)=3.87 \mu_{\mathrm{B}}$ for $\mathrm{Co}^{2+}$ ions on the $A$ sites with spin $S=3 / 2$ and $g=2$ since its tetrahedral coordination does not allow orbital contribution, yields $\mu(\mathrm{B})=4.91 \mu_{\mathrm{B}}$ for $\mathrm{Co}_{2} \mathrm{SnO}_{4}$. This

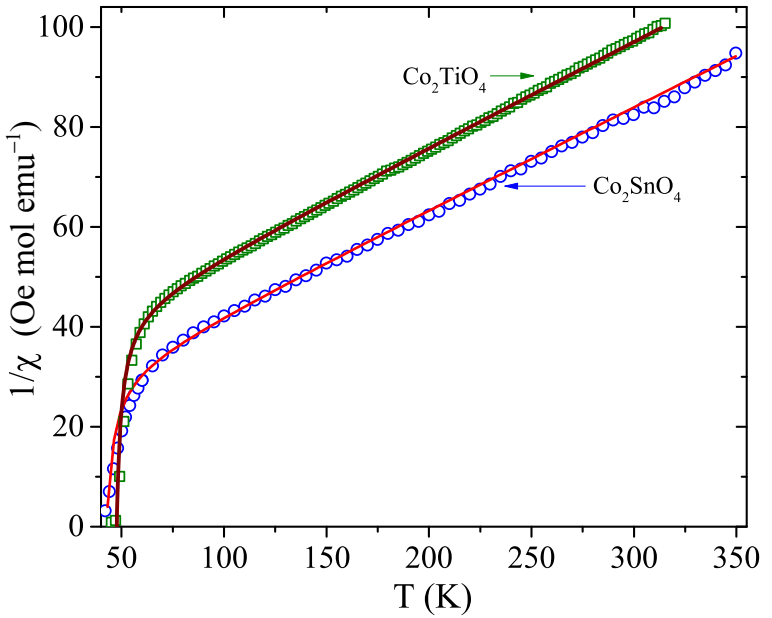

FIG. 4. (Color online) Temperature variation of the inverse paramagnetic susceptibility $\chi^{-1}(T)$ of $\mathrm{Co}_{2} \mathrm{TiO}_{4}$ and $\mathrm{Co}_{2} \mathrm{SnO}_{4}$ systems. The solid lines are best fits to the Néel's expression for ferrimagnets discussed in the text.

argument for $\mathrm{Co}_{2} \mathrm{SnO}_{4}$ yields ferrimagnetism below $T_{\mathrm{N}}$ with net small moment of $1.04 \mu_{\mathrm{B}}$ per f.u.

For $\mathrm{Co}_{2} \mathrm{TiO}_{4}$, with the electronic configuration of $\left[\mathrm{Co}^{2+}\right]\left[\mathrm{Co}^{3+} \mathrm{Ti}^{3+}\right] \mathrm{O}_{4}$ determined using XPS, the above analysis yields $\mu_{\text {eff }}=6.5 \mu_{\mathrm{B}}$ per f.u. Again, using $\mu(A)=3.87 \mu_{\mathrm{B}}$ for $\mathrm{Co}^{2+}$ ions on the $A$ site as in $\mathrm{Co}_{2} \mathrm{SnO}_{4}$ yields $\mu(B)=$ $5.19 \mu_{\mathrm{B}}$ for ions on the $B$ site. The trivalent titanium ion $\mathrm{Ti}^{3+}$ with its $3 d^{1}$ electronic configuration has magnetic moment $\mu=1.73 \mu_{\mathrm{B}}$ yielding $\mu\left(\mathrm{Co}^{3+}\right)=4.89 \mu_{\mathrm{B}}$ as the moment for the $\mathrm{Co}^{3+}$ ion on the $B$ site. In the high spin state, $\mathrm{Co}^{3+}$ ions should have spin only $\mu=4.9 \mu_{\mathrm{B}}$, which agrees with the above estimate. So an important conclusion from this comparative analysis of the paramagnetic susceptibilities is that $\mu_{\mathrm{eff}}=6.5 \mu_{\mathrm{B}}$ per f.u. of $\mathrm{Co}_{2} \mathrm{TiO}_{4}$ is higher than that in $\mathrm{Co}_{2} \mathrm{SnO}_{4}$. This leads to the calculated net ferrimagnetic moment of $\mu=1.32 \mu_{\mathrm{B}}$ per f.u. below $T_{\mathrm{N}}$, which is higher than $\mu=1.04 \mu_{\mathrm{B}}$ per f.u. of $\mathrm{Co}_{2} \mathrm{SnO}_{4}$ below its $T_{\mathrm{N}}$. This information is used below to explain the observed differences in the measured magnetic properties of $\mathrm{Co}_{2} \mathrm{TiO}_{4}$ against $\mathrm{Co}_{2} \mathrm{SnO}_{4}$ below $T_{\mathrm{N}}$. Another important difference between the two systems is that, in $\mathrm{Co}_{2} \mathrm{TiO}_{4}$, the $B$ site is occupied by $\mathrm{Co}^{3+}$ and $\mathrm{Ti}^{3+}$, both of which have magnetic moments unlike the case of $\mathrm{Co}_{2} \mathrm{SnO}_{4}$ in which the $\mathrm{Sn}^{4+}$ ion on the $B$ site does not have a magnetic moment. Therefore, the effects of magnetic dilution should be less prominent in $\mathrm{Co}_{2} \mathrm{TiO}_{4}$.

\section{B. Temperature dependence of the dc magnetic susceptibilities}

The temperature dependence of the dc magnetic susceptibilities $\chi_{\mathrm{dc}}=M / H_{\mathrm{dc}}$ determined from the measured magnetization $(M)$ in the presence of external magnetic field $H_{\mathrm{dc}}=50,100,500,1000$, and 10,000 Oe is shown in Fig. 5 for $\mathrm{Co}_{2} \mathrm{TiO}_{4}$. The data are shown for both the traditional ZFC and field cooled (FC) cases. The significant features of the data are $\chi$ peaking at a temperature near $46 \mathrm{~K}$, suggesting ferrimagnetic ordering, and a crossover in sign for $\chi$ (ZFC) and $\chi$ (FC) at a compensation temperature near $32 \mathrm{~K}$, where the magnetization of the two sublattices balance each other. 
TABLE II. The list of various parameters obtained from the Néel fits of $\chi^{-1}$ vs $T$ curve recorded under zero-field-cooled condition.

\begin{tabular}{cccccccc}
\hline \hline System & \multirow{2}{*}{$\left(\mathrm{emu} \mathrm{K} \mathrm{mol}^{-1} \mathrm{Oe}^{-1}\right)$} & $\chi_{\mathrm{o}}\left(\mathrm{emu} \mathrm{mol}^{-1} \mathrm{Oe}^{-1}\right)$ & $\sigma_{\mathrm{o}}\left(\mathrm{emu}^{-1} \mathrm{Oe} \mathrm{mol} \mathrm{K}\right)$ & $\theta(\mathrm{K})$ & $\mu_{\mathrm{eff}}\left(\mu_{\mathrm{B}}\right)$ & $\mu(A)\left(\mu_{\mathrm{B}}\right)$ & $\mu(B)\left(\mu_{\mathrm{B}}\right)$ \\
\hline $\mathrm{Co}_{2} \mathrm{TiO}_{4}$ & 5.245 & 0.0419 & 31.55 & 49.85 & 6.5 & 3.87 & 5.19 \\
& & $N_{A A}$ & $N_{A B}$ & $N_{B B}$ & $J_{A A}$ & $J_{A B}$ & $J_{B B}$ \\
& & 17.319 & 35.700 & 12.720 & $3.25 k_{\mathrm{B}}$ & $4.47 k_{\mathrm{B}}$ & $3.18 k_{\mathrm{B}}$ \\
$\mathrm{Co}_{2} \mathrm{SnO}_{4}$ & 4.889 & 0.0436 & 102.370 & 39.5 & 6.25 & 3.87 & 4.91 \\
& & $N_{A A}$ & $N_{A B}$ & $N_{B B}$ & $J_{A A}$ & $J_{A B}$ & $J_{B B}$ \\
& 21.564 & 33.201 & 10.678 & $4.05 k_{\mathrm{B}}$ & $5.26 k_{\mathrm{B}}$ & $4.28 k_{\mathrm{B}}$ \\
\hline \hline
\end{tabular}

These observations are similar to those reported by Hubsch and Gavoille [17] in $\mathrm{Co}_{2} \mathrm{TiO}_{4}$ and are discussed in more detail later. The temperature dependence of the magnetization $(M)$ for the ZFC and FC cases under applied $H_{\mathrm{dc}}=5,10,20,30$, and $40 \mathrm{kOe}$ is shown in Fig. 6. Several features of the data are noteworthy: (i) the compensation temperature $T_{\text {comp }} \simeq 32 \mathrm{~K}$ is independent of applied $H_{\mathrm{dc}}$, and compensation is not complete in that $M$ at $T_{\text {comp }}$ is not zero but increases with increase in $H_{\text {dc }}$; (ii) the position of the peak temperature near $46 \mathrm{~K}$ shifts slightly to higher temperatures with increase in $H_{\mathrm{dc}}$; and (iii) the temperature for which $M$ (FC) bifurcates from $M$ (ZFC) shifts to lower temperature with increase in $H_{\mathrm{dc}}$. Very similar features have been observed in other spinel compounds as well, for example, in the Ni-Fe-Sb-O spinel [30].

In order to compare the above observations in $\mathrm{Co}_{2} \mathrm{TiO}_{4}$ with similar measurements in $\mathrm{Co}_{2} \mathrm{SnO}_{4}$, new data on $\mathrm{Co}_{2} \mathrm{SnO}_{4}$ $[15,16]$ are shown in Fig. 7 for the ZFC and FC cases in $H=100,500,1000$, and 5000 Oe. Although there are some similarities with the data for $\mathrm{Co}_{2} \mathrm{TiO}_{4}$ in Fig. 5, the behavior near the compensation temperature of $32 \mathrm{~K}$ in $\mathrm{Co}_{2} \mathrm{TiO}_{4}$ is not observed in $\mathrm{Co}_{2} \mathrm{SnO}_{4}$. Instead, there is a bifurcation of the FC and ZFC data beginning near $7 \mathrm{~K}$, which is field independent, and a second bifurcation at higher temperatures, the location of which is field dependent. More information on these differences between the two systems become evident from the behavior of the hysteresis loop parameters discussed later.

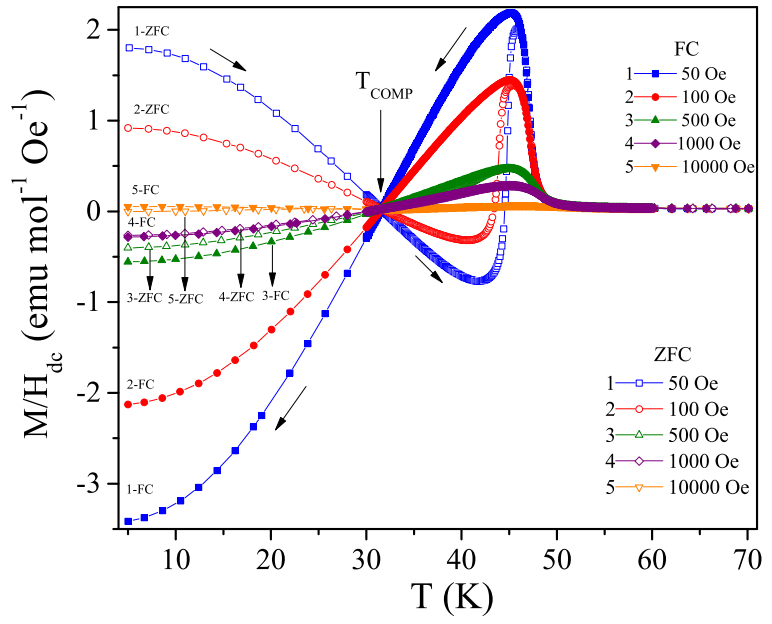

FIG. 5. (Color online) Temperature dependence of dc magnetic susceptibility $\chi(T)\left[=M / H_{\mathrm{dc}}(T)\right]$ for $\mathrm{Co}_{2} \mathrm{TiO}_{4}$ measured under both $\mathrm{ZFC}$ and $\mathrm{FC}$ conditions recorded at various magnetic fields in the range $50 \mathrm{Oe} \leqslant H_{\mathrm{dc}} \leqslant 10 \mathrm{kOe}$.

\section{Temperature dependence of the ac magnetic susceptibility}

The temperature dependence of the ac magnetic susceptibilities $\chi^{\prime}$ and $\chi^{\prime \prime}$ were measured using a frequency of $2 \mathrm{~Hz}$ with $h_{\mathrm{ac}}=4$ Oe superimposed with various dc fields $H_{\mathrm{dc}}$ between $0,10,20$, and 30 Oe. The results of the plots of $\chi^{\prime}$ and $\chi^{\prime \prime}$ vs temperature in Fig. 8 show splitting of a single peak near $46.5 \mathrm{~K}$ into two peaks when $H_{\mathrm{dc}}$ is increased. In the $\chi^{\prime}$ vs $T$ data, the higher temperature peak shifts to the higher temperature side with increase in $H_{\mathrm{dc}}$, whereas the reverse is true for the lower temperature peak. The transition at $46.5 \mathrm{~K}$ was probed further by measuring temperature dependence of $\chi^{\prime}$ and $\chi^{\prime \prime}$ at nine different frequencies $f_{m}$ between 0.17 and $1202 \mathrm{~Hz}$ using $h_{\mathrm{ac}}=4 \mathrm{Oe}$ and $H_{\mathrm{dc}}=0$. The results are plotted in Fig. 9. For $\chi^{\prime}$, the peak at $46.8 \mathrm{~K}$ measured at the lowest frequency of $0.17 \mathrm{~Hz}$ shifts to higher temperatures with increase in frequency, approaching near $47.11 \mathrm{~K}$ at $f_{m}=1202 \mathrm{~Hz}$.

This kind of frequency dependence of the peak in the ac susceptibility curves seems to be qualitatively quite similar to what we had observed earlier in $\mathrm{Co}_{2} \mathrm{SnO}_{4}$ [16]. However, a detailed quantitative analysis of the data revealed a marked difference between the two systems. As in the case of $\mathrm{Co}_{2} \mathrm{SnO}_{4}$ [16], we tried to analyze the frequency dependence seen in $\mathrm{Co}_{2} \mathrm{TiO}_{4}$ using two scaling laws: (i) the Vogel-Fulcher law, which is given by the expression $\tau=\tau_{0} \exp \left[\frac{E_{a}}{k_{\mathrm{B}}\left(T-T_{0}\right)}\right]$, where $\tau_{0}$ is the relaxation time constant, $T_{0}$ is a measure of the interaction between magnetic clusters, $k_{\mathrm{B}}$ is the Boltzmann constant, and $E_{a}$ is an activation energy parameter; and (ii) the power

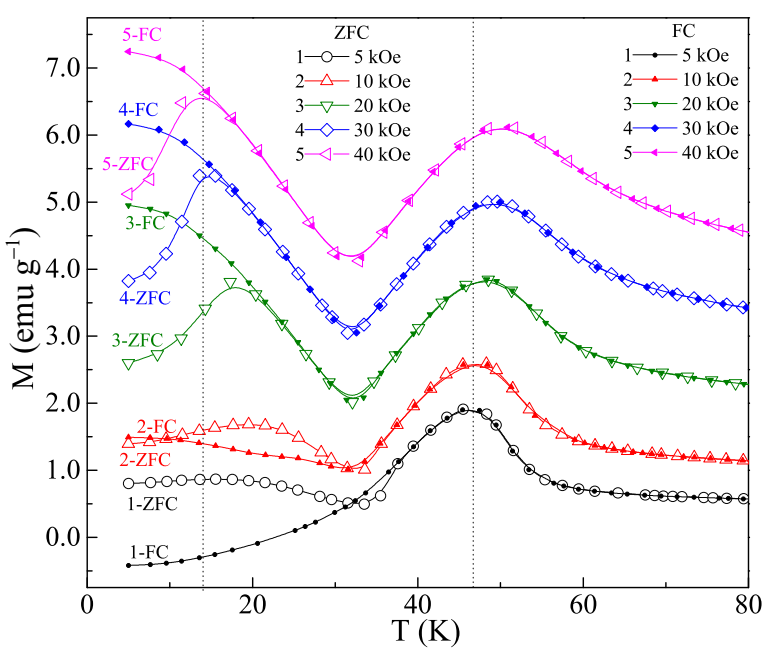

FIG. 6. (Color online) High-field ( $\left.5 \mathrm{kOe} \leqslant H_{\mathrm{dc}} \leqslant 40 \mathrm{kOe}\right)$ magnetization $(M)$ vs temperature $(T)$ data for $\mathrm{Co}_{2} \mathrm{TiO}_{4}$ measured under both the ZFC and FC conditions. 


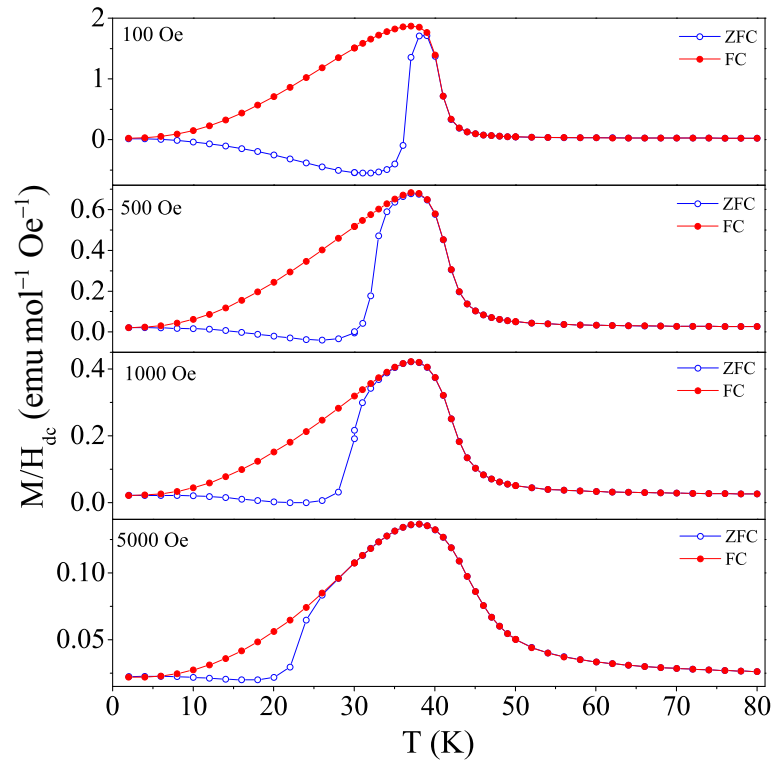

FIG. 7. (Color online) Temperature dependence of dc magnetic susceptibility $\chi(T)\left[=M / H_{\mathrm{dc}}(T)\right]$ for $\mathrm{Co}_{2} \mathrm{SnO}_{4}$ measured under both $\mathrm{ZFC}$ and FC conditions recorded at various magnetic fields.

law, which describes the critical slowing down in a spin-glass phase transition at $T_{g}$, and is given by $\tau=\tau_{0}\left[\left(\frac{T}{T_{g}}\right)-1\right]^{-z v}$, where $T_{g}$ is the freezing temperature, $\tau_{0}$ is related to the relaxation of the individual cluster magnetic moment, and $z v$ is a critical exponent. Here, $\tau=\frac{1}{\omega}=\frac{1}{2 \pi f}$. While for $\mathrm{Co}_{2} \mathrm{SnO}_{4}$ [16], we could obtain physically reasonable fit parameters using both the Vogel-Fulcher law as well as the power law albeit using a very limited temperature range, for $\mathrm{Co}_{2} \mathrm{TiO}_{4}$, the situation is different. In Fig. 10, we show the best representation of the data that was obtained using the Vogel-Fulcher law, with $T_{0}=45.8 \mathrm{~K}$ and $\tau_{0}=3.2 \times 10^{-16} \mathrm{~s}$.

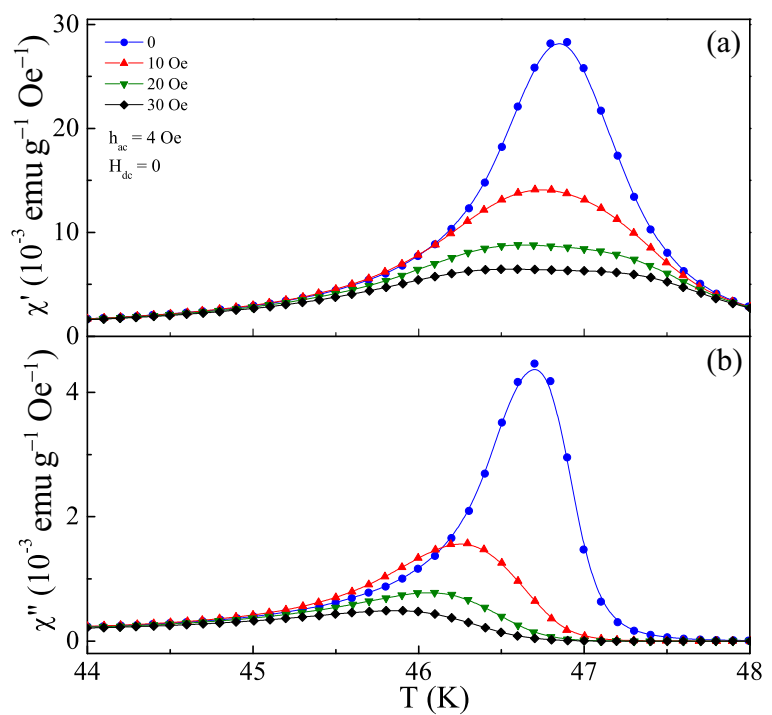

FIG. 8. (Color online) (a) Temperature variation of the ac magnetic susceptibility (a) $\chi^{\prime}(T)$, and (b) $\chi^{\prime \prime}(T)$ for $\mathrm{Co}_{2} \mathrm{TiO}_{4}$ measured at $2 \mathrm{~Hz}$ in $h_{\mathrm{ac}}=4 \mathrm{Oe}$ with superposed dc bias fields $H_{\mathrm{dc}}=0,10,20$, and $30 \mathrm{Oe}$.

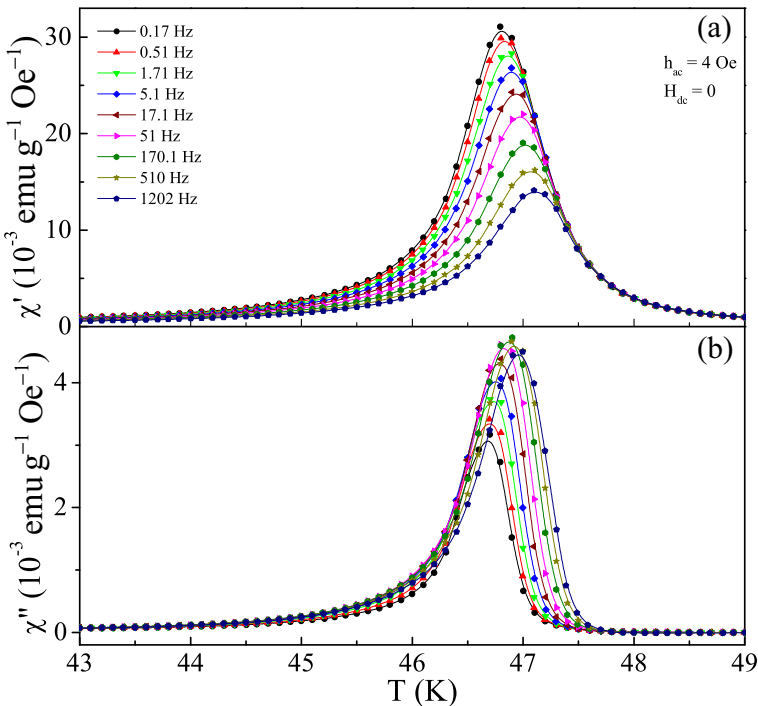

FIG. 9. (Color online) Temperature dependence of ac magnetic susceptibilities (a) $\chi^{\prime}(T)$ and (b) $\chi^{\prime \prime}(T)$ of $\mathrm{Co}_{2} \mathrm{TiO}_{4}$ measured at various frequencies between 0.17 and $1202 \mathrm{~Hz}$ under warming conditions using $h_{\mathrm{ac}}=4 \mathrm{Oe}$ and $H_{\mathrm{dc}}=0$ Oe.

However, an attempt to fit the data using the power law, yielded quite unphysical values of the fit parameters (viz. $\tau_{0} \sim 10^{-33} \mathrm{~s}$ and $z v>16$ ), indicating the lack of SG phase transition.

\section{Temperature dependence of the hysteresis loop parameters}

Hysteresis loop measurements of $M$ vs $H$ for the $\mathrm{Co}_{2} \mathrm{TiO}_{4}$ sample were performed at selected temperatures between 5 and $60 \mathrm{~K}$ in the magnetic field range of -90 to $+90 \mathrm{kOe}$. The measurements were done in the ZFC (FC) protocol in which the sample is cooled in $H_{\mathrm{dc}}=0 \mathrm{Oe}\left(H_{\mathrm{dc}}=20 \mathrm{kOe}\right)$ from the paramagnetic state to the measuring temperature followed by measurements of $M$ vs $H$. For the data at the next temperature, the sample was again warmed to the paramagnetic state and cooled back similarly to the next measurement temperature. Hysteresis loops at four selected

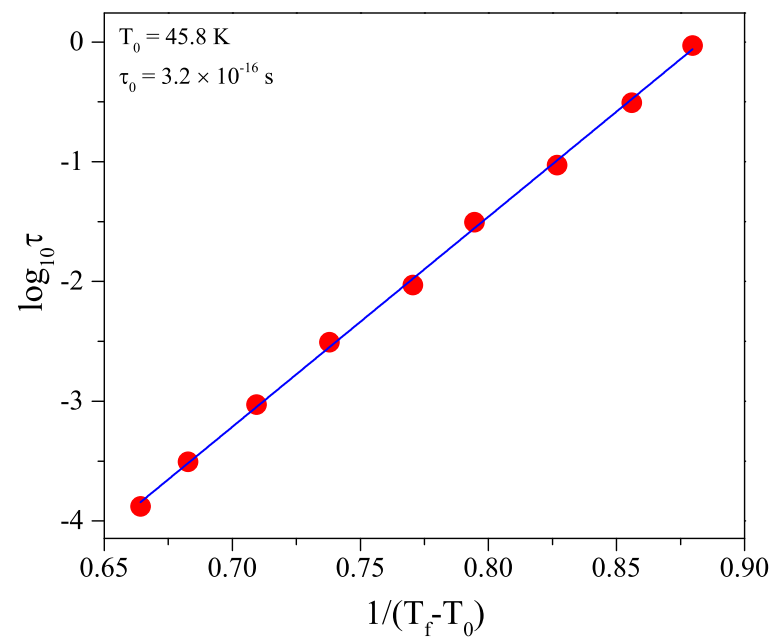

FIG. 10. (Color online) The best fit of the relaxation times to the Vogel-Fulcher law in $\mathrm{Co}_{2} \mathrm{TiO}_{4}$. 


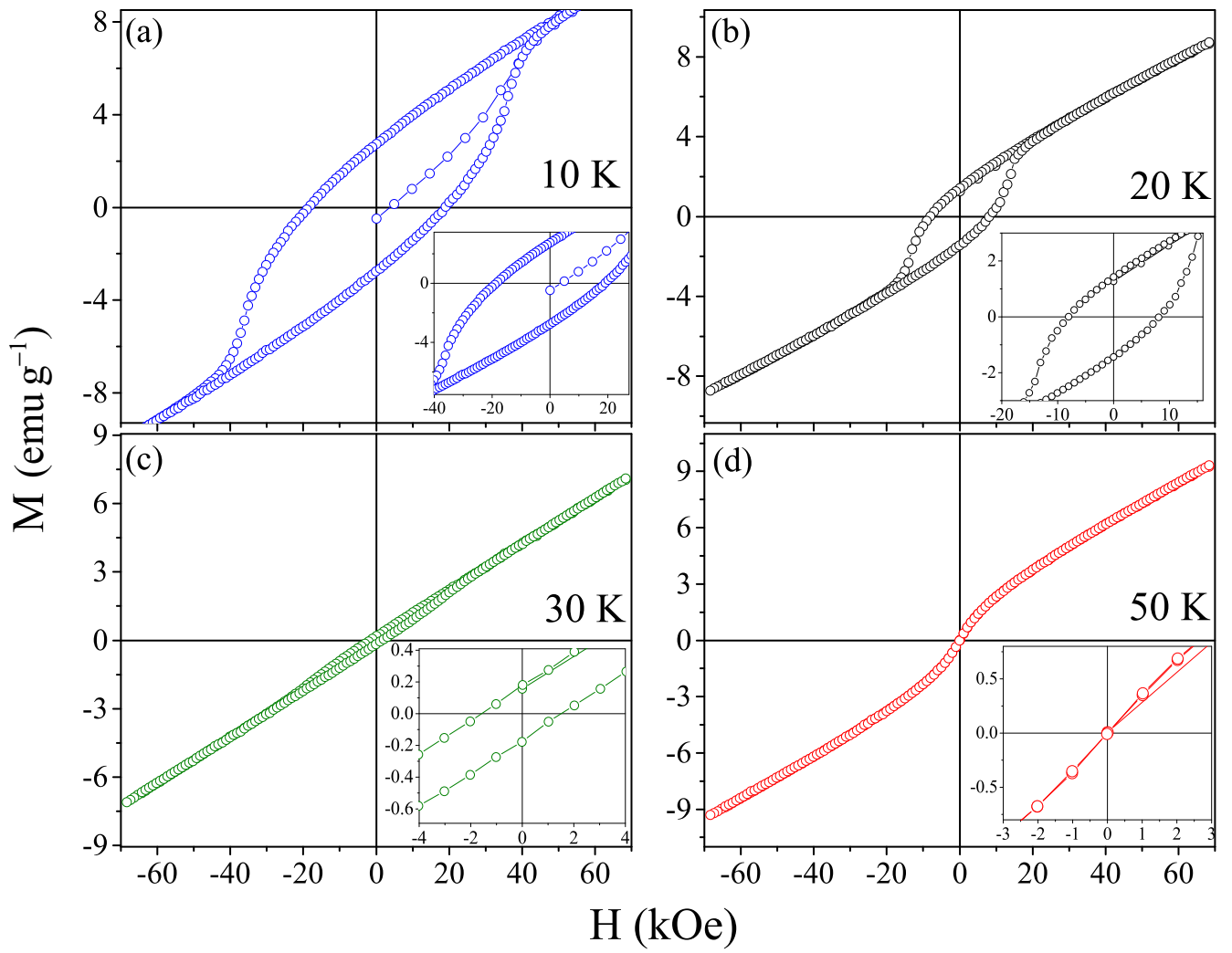

FIG. 11. (Color online) Plots of hysteresis loops $\left(M \mathrm{vs} H\right.$ ) in $\mathrm{Co}_{2} \mathrm{TiO}_{4}$ are shown at selected temperatures of (a) $10 \mathrm{~K}$, (b) $20 \mathrm{~K}$, (c) $30 \mathrm{~K}$, and (d) $50 \mathrm{~K}$ recorded under ZFC condition. The insets show the zoomed view of $M-H$ loops near origin showing the asymmetry in the loops.

temperatures shown in Fig. 11 show that a weak ferromagnetic component $M_{\mathrm{WF}}$ is superimposed on a linear component with $M_{\mathrm{WF}}$ strongly temperature dependent. The inset of the Fig. 12 shows asymmetry in the $M-H$ loops measured at $5 \mathrm{~K}$ under $\mathrm{ZFC}$ and $\mathrm{FC}( \pm 20 \mathrm{kOe})$ protocol. The standard definition of the coercivity is $H_{\mathrm{C}}=\left(H^{+}-H^{-}\right) / 2$, and loop shift is $H_{\mathrm{EB}}=\left(H^{+}+H^{-}\right) / 2$, where $H^{+}\left(H^{-}\right)$are magnetic field values for which $M=0$, and the remanence $M_{\mathrm{R}}$ for

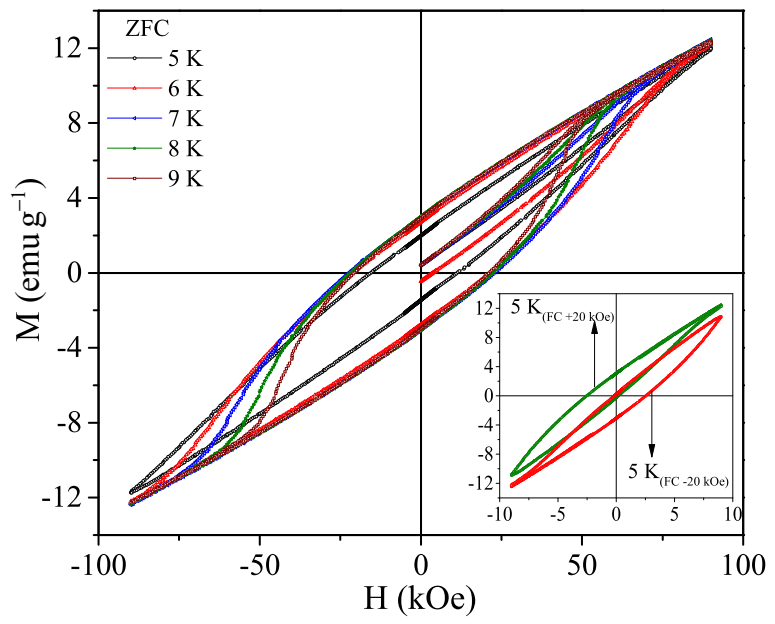

FIG. 12. (Color online) The hysteresis loops ( $M$ vs $H$ ) measured at low temperatures 5, 6, 7, 8, and $9 \mathrm{~K}$ under ZFC condition. The insets show the asymmetry in the $M-H$ loops measured at $5 \mathrm{~K}$ under FC (20 kOe) condition. the magnetization at $H=0$ are used along with $M_{\max }$, the measured magnetization at $90 \mathrm{kOe}$ [shown in Figs. 13(a) and 13(b)]. Note that, below $10 \mathrm{~K}$, all the $M-H$ data appear like minor loops; thus, extracted magnitudes of $H_{\mathrm{C}}, H_{\mathrm{EB}}$, and $M_{\mathrm{R}}$ are underestimated significantly. Due to this reason, we do not show the data for $T<10 \mathrm{~K}$. Particularly noteworthy are the large magnitudes of $H_{\mathrm{C}} \sim 20 \mathrm{kOe}$. In addition, there is a minimum in $M_{\mathrm{R}}$ and $M_{\max }$ at $30 \mathrm{~K}$, the temperature for which partial compensation of the two sublattices was indicated in Figs. 5 and 6. Observation of nonzero $M_{\mathrm{R}}$ is evidence for the presence of $M_{\mathrm{WF}}$. We will return to the discussion of these results and their significance later in Sec. V.

For comparison, Fig. 14 shows the temperature dependence of $H_{\mathrm{C}}$ and $H_{\mathrm{EB}}$ for the $\mathrm{Co}_{2} \mathrm{SnO}_{4}$ system. In this case, a hysteresis loop is observed only between 10 and $35 \mathrm{~K}$ with a peak in $H_{\mathrm{C}}$ occurring at $20 \mathrm{~K}$, and there is no difference in the magnitude of $H_{\mathrm{C}}$ for the $\mathrm{ZFC}$ case and the $\mathrm{FC}$ case in which the sample was cooled in $H=10 \mathrm{kOe}$ from well above $T_{\mathrm{N}}$. The exchange bias $H_{\mathrm{EB}}$ is observed only for the FC case.

\section{E. Temperature dependence of the specific heat}

The plots of the temperature dependence of the specific heat $C_{\mathrm{p}}(T)$ of $\mathrm{Co}_{2} \mathrm{TiO}_{4}$ measured in $H_{\mathrm{dc}}=0,10$ and $50 \mathrm{kOe}$ are shown in Fig. 15. From 5 to $28 \mathrm{~K}$, the data were taken at temperature intervals of $2 \mathrm{~K}$ and from 28 to $60 \mathrm{~K}$ in steps of $1 \mathrm{~K}$. In $H_{\mathrm{dc}}=0 \mathrm{Oe}$, a single shoulder in $C_{\mathrm{p}}$ vs $T$ is observed at $T_{\mathrm{N}}=47.8 \mathrm{~K}$, very similar to the earlier studies by Ogawa and Waki [20]. In applied field of 10 and $50 \mathrm{kOe}$, this peak becomes diffuse and shifts by a few degrees to higher temperatures (see 


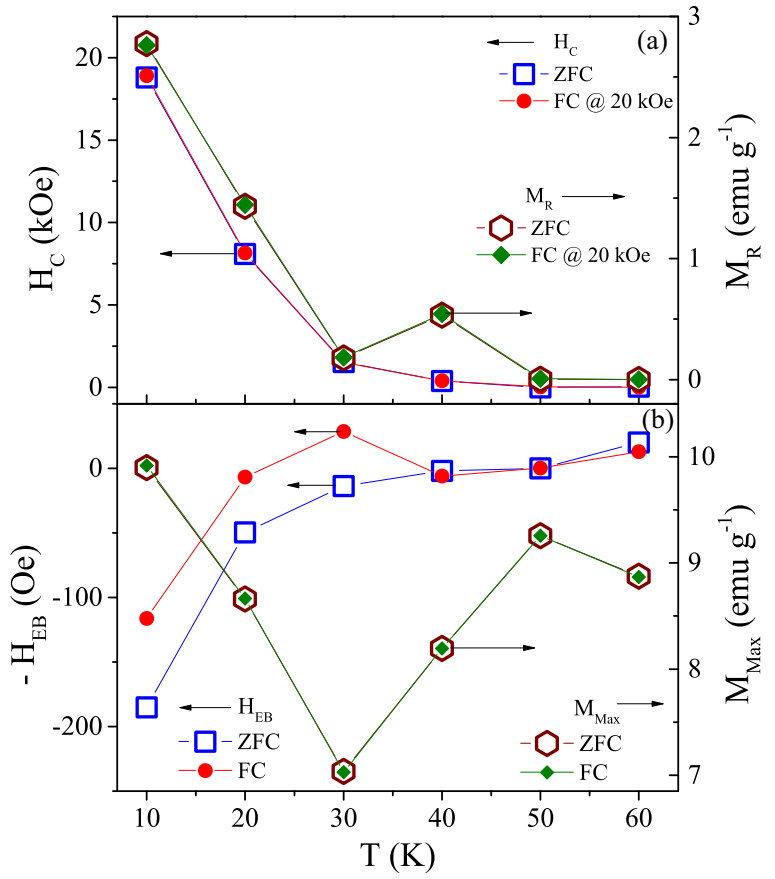

FIG. 13. (Color online) The temperature variation of (a) coercive field $H_{\mathrm{C}}(T)$ and remanence magnetization $M_{\mathrm{R}}$ and (b) exchange bias $H_{\mathrm{EB}}(T)$ and high field $(H \sim 90 \mathrm{kOe})$ magnetization $M_{\max }$ measured under both ZFC and FC (20 kOe) conditions in $\mathrm{Co}_{2} \mathrm{TiO}_{4}$. The lines connecting the data points are visual guides.

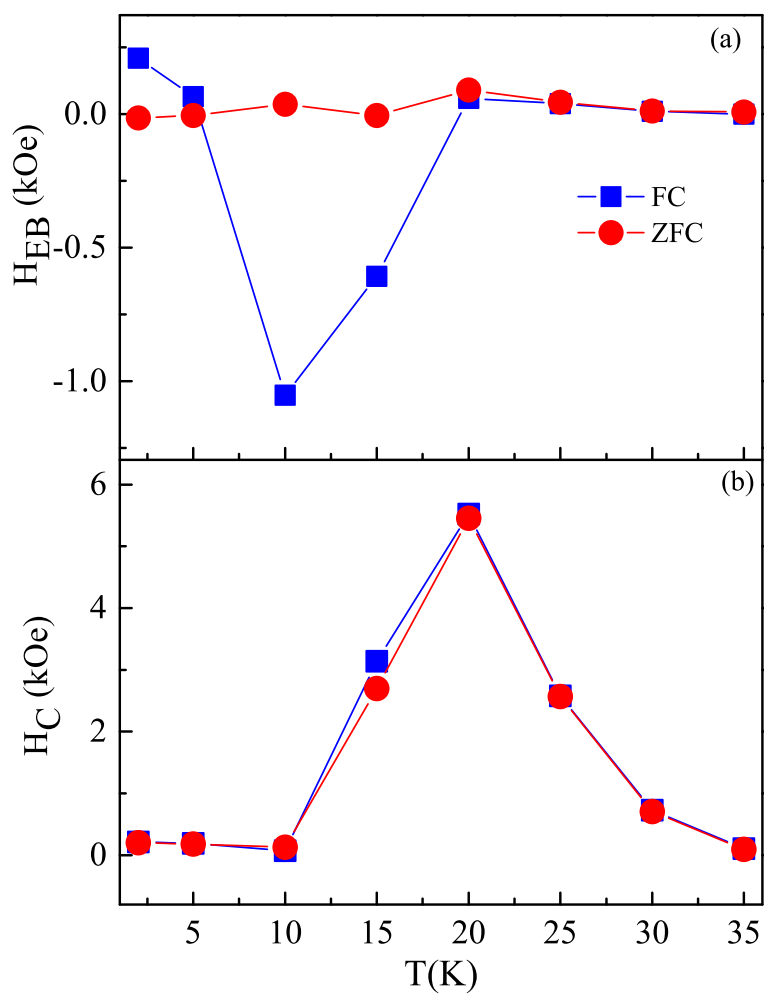

FIG. 14. (Color online) Temperature variations of (a) exchange bias $H_{\mathrm{EB}}$ and (b) coercivity $\mathrm{H}_{\mathrm{C}}$ in $\mathrm{Co}_{2} \mathrm{SnO}_{4}$ for the ZFC and FC (@ $10 \mathrm{kOe}$ ) cases. The lines connecting the data points are visual guides.

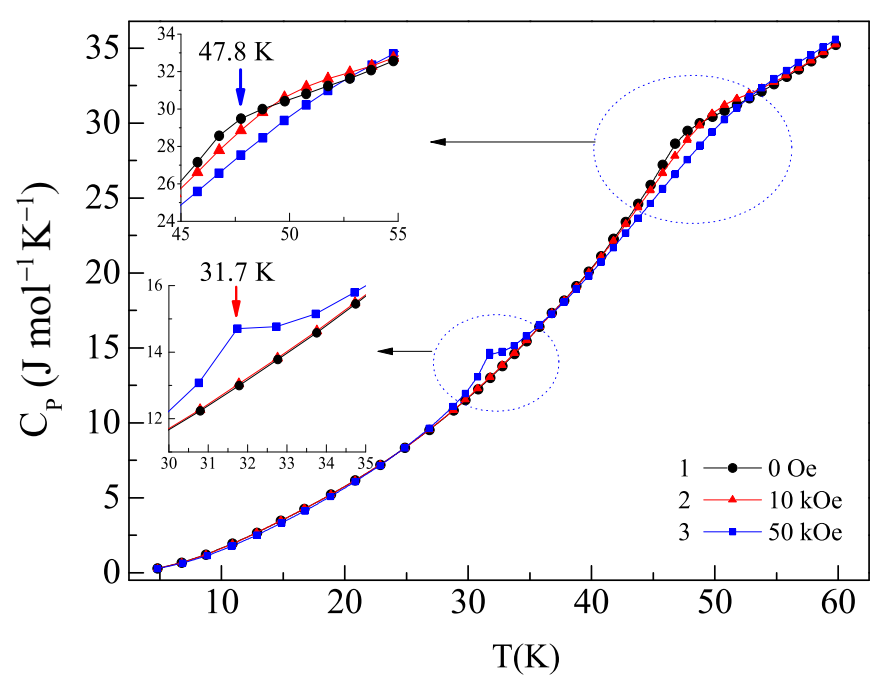

FIG. 15. (Color online) The temperature variation of specific heat $C_{\mathrm{p}}(T)$ for the $\mathrm{Co}_{2} \mathrm{TiO}_{4}$ sample recorded at various magnetic fields $\left(H_{\mathrm{dc}}=0,10\right.$, and $\left.50 \mathrm{kOe}\right)$. The insets show the zoomed view across the ferrimagnetic Néel temperature $\left(T_{\mathrm{N}}\right)$ and compensation temperature $\left(T_{\text {comp }}\right)$.

inset of Fig. 15). Interestingly, another peak is observed at $31.7 \mathrm{~K}$ when $H_{\mathrm{dc}}=50 \mathrm{kOe}$, suggesting some relationship of this peak with the compensation temperature noted above from $M$ vs $T$ data in Figs. 5 and 6.

As discussed in our paper on $\mathrm{Co}_{2} \mathrm{SnO}_{4}$ [16], magnetic entropy $S_{\mathrm{M}}$ and magnetic specific heat are related by the thermodynamic relation $d\left(S_{\mathrm{M}}\right) / d T=C_{\mathrm{M}} / T$. Since it is difficult to accurately separate out the lattice contribution to $C_{\mathrm{p}}$, we have plotted $C_{\mathrm{p}} / T$ vs temperature in Fig. 16 to get additional information on the magnetic ordering. The slight shift and blurring of $T_{\mathrm{N}}$ at $47.8 \mathrm{~K}$ to higher temperatures with increasing $H$ is evident, in addition to a peak near $32 \mathrm{~K}$ and a weaker anomaly around $10 \mathrm{~K}$. The fact that the peak in $C_{\mathrm{p}}$ at $T_{\mathrm{N}}$ in $H_{\mathrm{dc}}=0$ is quite weak (almost like a shoulder) compared to peaks observed in typical second-order transitions in three-dimensional (3D) systems is due to unconventional

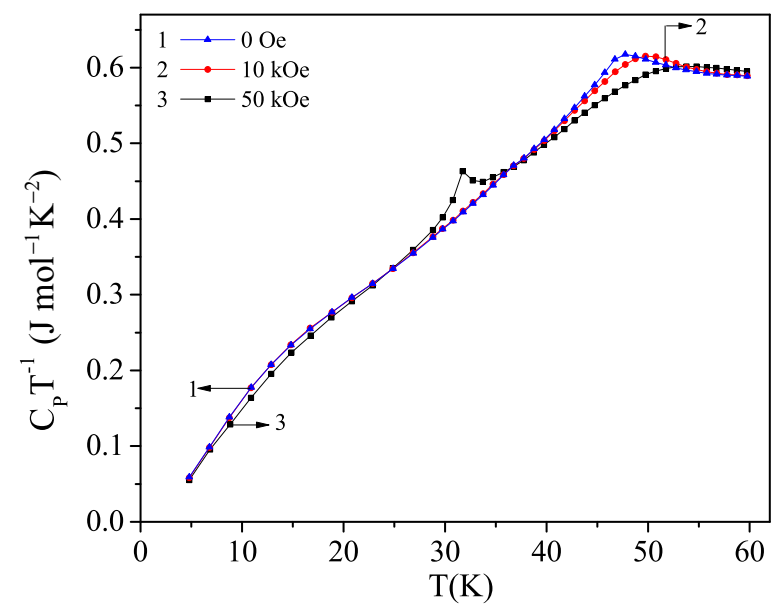

FIG. 16. (Color online) The temperature dependence of $C_{\mathrm{p}} T^{-1}$ for the $\mathrm{Co}_{2} \mathrm{TiO}_{4}$ sample using the data of Fig. 15 . 
ordering in $\mathrm{Co}_{2} \mathrm{TiO}_{4}$ viz. rather in between second-order transition in $3 \mathrm{D}$ system and spin-glasses, the latter showing no peak in $C_{\mathrm{p}}$ at $T_{\mathrm{SG}}$. Significance of these results and their comparison with earlier studies of $\mathrm{Co}_{2} \mathrm{TiO}_{4}$ and our recent studies of $\mathrm{Co}_{2} \mathrm{SnO}_{4}$ are presented in the following section.

\section{DISCUSSION}

The paper by Hubsch and Gavoille [17] on the nature of magnetic ordering in $\mathrm{Co}_{2} \mathrm{TiO}_{4}$ reported $T_{\mathrm{N}}=55 \mathrm{~K}$ followed by spin-glass ordering at $T_{\mathrm{SG}}=46 \mathrm{~K}$. However, between 55 and $46 \mathrm{~K}$, the remanence $M_{\mathrm{R}}$ was extremely small, reaching a peak value of only about $0.05 \mathrm{emu} / \mathrm{g}$ at $50 \mathrm{~K}$, and then becoming zero again at $46 \mathrm{~K}$. Below $46 \mathrm{~K}, M_{\mathrm{R}}$ increased rapidly, peaking at $M_{\mathrm{R}}=0.7 \mathrm{emu} / \mathrm{g}$ at $40 \mathrm{~K}$ before compensation sets in. In the $C_{\mathrm{p}}$ vs $T$ measurements of Ogawa and Waki [20] and in our studies reported here in Fig. 15, a peak in $C_{\mathrm{p}}$ is observed only near $48 \mathrm{~K}$, although under nonzero applied $H_{\mathrm{dc}}$, this feature becomes more diffused and shifts to higher temperatures.

The phenomenon of compensation observed near $32 \mathrm{~K}$ in Figs. 5 and 6 confirms the earlier observation of Hubsch and Gavoille [17] However, the compensation in $\mathrm{Co}_{2} \mathrm{TiO}_{4}$ is not complete in that the magnetization measured at the minimum is not quite zero, and it increases as the magnetic field used for the measurements is increased. In ferrimagnets with different magnetic moments on the $A$ and the $B$ sites and which also have different temperature dependence, a complete compensation or at least a minimum in the observed moment $\mu(T)=\mu(A)-\mu(B)$ could occur at a certain temperature below $T_{\mathrm{N}}$ [15].This is clearly observed here in $\mathrm{Co}_{2} \mathrm{TiO}_{4}$ in both the measured $M$ (Figs. 5 and 6) and in $M_{\mathrm{R}}$ [Fig. 13(a)]. The estimated magnetic moments on the $A$ and the $B$ sites of $\mathrm{Co}_{2} \mathrm{TiO}_{4}$ are sufficiently different with $\mu(A)=3.87 \mu_{\mathrm{B}}$ and $\mu(B)=5.19 \mu_{\mathrm{B}}$, as discussed earlier in Sec. IV A. For comparison, in $\mathrm{Co}_{2} \mathrm{SnO}_{4}$ with smaller difference in $\mu(A)=$ $3.87 \mu_{\mathrm{B}}$ and $\mu(B)=4.91 \mu_{\mathrm{B}}$, compensation is not as evident and clear cut, but below about $7 \mathrm{~K}$, there is effectively no remanence or coercivity implying compensation. Another evidence for the difference in the two systems in this regard is the difference in the measured remanence $M_{\mathrm{R}}$. For $\mathrm{Co}_{2} \mathrm{SnO}_{4}$, a maximum in $M_{\mathrm{R}}=0.45 \mathrm{emu} / \mathrm{g}$ is observed near $30 \mathrm{~K}$ [16], whereas in $\mathrm{Co}_{2} \mathrm{TiO}_{4}$, a maximum in $M_{\mathrm{R}}=3 \mathrm{emu} / \mathrm{g}$ observed near $10 \mathrm{~K}$ is a factor of about six larger. The ratio of the observed $M_{\mathrm{R}}$ in $\mathrm{Co}_{2} \mathrm{TiO}_{4}$ and $\mathrm{Co}_{2} \mathrm{SnO}_{4}$ scales well with the difference in their $\mu(A)$ and $\mu(B)$ values when normalized with their molecular weights.

The temperature dependence of coercivity $H_{\mathrm{C}}(T)$ and exchange bias $H_{\mathrm{EB}}(T)$ shown in Figs. 13(a) and 13(b) is considered next. In the Stoner-Wohlfarth (SW) model of coercivity in single-domain particle, $H_{\mathrm{C}}=K_{\mathrm{A}} / M_{\mathrm{S}}$, where $K_{\mathrm{A}}$ is the magnetocrystalline anisotropy constant and $M_{\mathrm{S}}$ is the saturation magnetization [31]. Below $T_{\mathrm{N}}, K_{\mathrm{A}} \sim\left(M_{\mathrm{S}}\right)^{n}$, where $n$ is system dependent and can be as large as 10 [31]. Therefore, in the SW model, $H_{\mathrm{C}}$ should continue to increase with decrease in temperature below $T_{\mathrm{N}}$. In the plot of $H_{\mathrm{C}}$ vs $T$ in Fig. 13(a) for $\mathrm{Co}_{2} \mathrm{TiO}_{4}$, an increase in $H_{\mathrm{C}}$ with a decrease in $T$ is observed, reaching a peak at about $10 \mathrm{~K}$ below which $H_{\mathrm{C}}$ decreases, and it is accompanied by the appearance of a very significant
$H_{\mathrm{EB}}$. In real systems, $H_{\mathrm{C}}$ is affected by impurities and grain boundaries which pin down the domain walls and prevent their rotation as the magnetic field is varied. The $M$ vs $T$ plot of Fig. 6 shows that, below $T_{\text {comp }}$, the FC and ZFC curves bifurcate at a certain temperature $T_{\mathrm{b}}$, which decreases as $H_{\mathrm{dc}}$ increases. This is similar to the observation reported in $\mathrm{Ni}$-hydroxide layered systems [32,33], where this phenomenon was associated with the blocking temperature of nanocrystallites. In both $\mathrm{Co}_{2} \mathrm{TiO}_{4}$ and $\mathrm{Co}_{2} \mathrm{SnO}_{4}$, the crystallite size is in the micrometer range. However, because of the substitution of the different magnetic ions with different magnetic moments on the $B$ sites, the formation of magnetic clusters is very likely. The bifurcation of the $M$ (FC) and $M$ (ZFC) curves in Figs. 6 and 7 at a specific temperature $T_{\mathrm{b}}$, which decreases with increase in $H_{\mathrm{dc}}$, may thus be due to freezing of these magnetic clusters. The observations of very large $H_{\mathrm{C}}$ and $H_{\mathrm{EB}}$-like behavior at $10 \mathrm{~K}$ in $\mathrm{Co}_{2} \mathrm{TiO}_{4}$ could thus result from the inability of the spins in the frozen clusters to follow the magnetic field.

Another noteworthy result in $\mathrm{Co}_{2} \mathrm{TiO}_{4}$ is the lack of saturation of the magnetization in $H$ up to $90 \mathrm{kOe}$ (Figs. 11 and 12). In the results reported by Hubsch and Gavoille [17], lack of saturation was evident even up to $150 \mathrm{kOe}$. These results suggest noncollinear ordering of spins in $\mathrm{Co}_{2} \mathrm{TiO}_{4}$. Preliminary neutron diffraction measurements by Hubsch and Gavoille [17] were evidence for the canting of the spins, which is consistent with nonsaturation of the magnetization. Qualitatively, this situation may be akin to that in the spinel $\mathrm{Mn}_{3} \mathrm{O}_{4}$ for which the two sublattices were found to be inadequate to describe the magnetic structure below $T_{\mathrm{N}}$ [34]. In $\mathrm{Co}_{2} \mathrm{TiO}_{4}$, the $B$ sites are occupied by two different magnetic ions, $\mathrm{Co}^{3+}$ and $\mathrm{Ti}^{3+}$, as reported here; therefore, at least a three-sublattice model is necessary to describe its magnetic structure. Srivastava et al. [7] have discussed a three-sublattice model in which magnitudes of the saturation magnetization and temperature dependence of paramagnetic susceptibility are used to solve for the exchange constants. Since, in $\mathrm{Co}_{2} \mathrm{TiO}_{4}$, magnetization does not saturate even up to $150 \mathrm{kOe}$, as noted above, this model cannot be applied to $\mathrm{Co}_{2} \mathrm{TiO}_{4}$. Thus, determining the nature of magnetic ordering of the spins below $T_{\mathrm{N}}$ in $\mathrm{Co}_{2} \mathrm{TiO}_{4}$ remains an outstanding challenge, both experimentally and theoretically.

\section{CONCLUDING REMARKS}

Results and their analysis on the structural and magnetic properties of $\mathrm{Co}_{2} \mathrm{TiO}_{4}$ are presented here along with a comparison with the properties of the isostructural compound $\mathrm{Co}_{2} \mathrm{SnO}_{4}$, reported here as well as in published papers recently $[15,16]$. The major results are as follows: (i) analysis of the temperature dependence of the dc susceptibilities above $T_{\mathrm{N}}$ using the Néel expression for ferrimagnets yields magnetic moments $\mu(A)=3.87 \mu_{\mathrm{B}}$ and $\mu(B)=5.19 \mu_{\mathrm{B}}\left(4.91 \mu_{\mathrm{B}}\right)$ for $\mathrm{Co}_{2} \mathrm{TiO}_{4}\left(\mathrm{Co}_{2} \mathrm{SnO}_{4}\right), \mu(B)$ being significantly different for the two cases; this difference in $\mu(B)$ is the major reason for differences in their magnetic properties; (ii) analysis of the XPS data shows the electronic structure of $\mathrm{Co}_{2} \mathrm{TiO}_{4}$ to be $\left[\mathrm{Co}^{2+}\right]\left[\mathrm{Co}^{3+} \mathrm{Ti}^{3+}\right] \mathrm{O}_{4}$ as compared to $\left[\mathrm{Co}^{2+}\right]\left[\mathrm{Co}^{2+} \mathrm{Sn}^{4+}\right] \mathrm{O}_{4}$ for $\mathrm{Co}_{2} \mathrm{SnO}_{4}$. This difference in the electronic structures of 
the ions on the $B$ sites is used to explain the difference in the observed $\mu(B)$ values and the lack of definite evidence for the presence of spin-glass transition in $\mathrm{Co}_{2} \mathrm{TiO}_{4}$ in contrast to the observation in $\mathrm{Co}_{2} \mathrm{SnO}_{4}$; (iii) a compensation temperature of $T_{\text {comp }} \simeq 32 \mathrm{~K}$ is observed for $\mathrm{Co}_{2} \mathrm{TiO}_{4}$ below which the system retains its ferrimagnetic character. In contrast, a similar compensation point is not observed in $\mathrm{Co}_{2} \mathrm{SnO}_{4}$, although below $7 \mathrm{~K}$, there is no coercivity or remanence which would be signatures of a compensated state; and (iv) the large magnitudes of the coercivity $H_{C}$ observed in $\mathrm{Co}_{2} \mathrm{TiO}_{4}$ in the uncompensated state most likely results from spin clusters. Also, the observed field-dependent magnetization reversal and lack of saturation of the magnetization in $\mathrm{Co}_{2} \mathrm{TiO}_{4}$ below its $T_{\mathrm{N}}$ in magnetic fields up to $150 \mathrm{kOe}$ suggest complex canting of the spins, which can be best determined by neutron diffraction measurements. It is hoped that the results presented here will provide the motivation for additional investigations.

\section{ACKNOWLEDGMENTS}

S.T. acknowledges the support from Deutscher Akademischer Austauschdienst (DAAD) Indian Institute of Technology (IIT) Faculty Exchange Programme of German Academic Exchange Service (Ref. No. 91563028). S.N. and D.C.J. acknowledge Fund for Improvement of Science and Technology (FIST) programme of Department of Science and Technology, India, for partial support of this work (Grant No. SR/FST/PSII-020/2009). T.S., M.S.A., and R.M. acknowledge financial support from the Swedish Research Council (VR). S.T. acknowledges the facilities provided by Science and Engineering Research Board (SERB)/Department of Science and Technology (DST) under Young Scientist Scheme (YSS) (Ref. No. YSS/2014/000340) and Department of Atomic Energy (DAE)-Board of Research in Nuclear Sciences (BRNS) under Young Scientist Research Award (YSRA) (Grant No. 34/20/02/2015/BRNS).
[1] E. W. Gorter, Phillips Res. Rep. 9, 295 (1954); F. K. Lotgering, ibid. 11, 190 (1956).

[2] V. G. Harris, A. Geiler, Y. Chen, S. D. Yoon, M. Wu, A. Yang, Z. Chen, P. He, P. V. Parimi, X. Zuo, C. E. Patton, M. Abe, O. Acher, and C. Vittoria, J. Magn. Magn. Mater. 321, 2035 (2009) and references therein.

[3] D. Fiorani, S. Viticoli, J. L. Dormann, J. L. Tholence, and A. P. Murani, Phys. Rev. B 30, 2776 (1984).

[4] W. Schiessl, W. Potzel, H. Karzel, M. Steiner, G. M. Kalvius, A. Martin, M. K. Krause, I. Halevy, J. Gal, W. Schäfer, G. Will, M. Hillberg, and R. Wäppling, Phys. Rev. B 53, 9143 (1996).

[5] C. E. Rodríguez Torres, G. A. Pasquevich, P. Mendoza Zélis, F. Golmar, S. P. Heluani, S. K. Nayak, W. A. Adeagbo, W. Hergert, M. Homann, A. Ernst, P. Esquinazi, and S. J. Stewart, Phys. Rev. B 89, 104411 (2014).

[6] K. Kamazawa, Y. Tsunoda, H. Kadowaki, and K. Kohn, Phys. Rev. B 68, 024412 (2003).

[7] C. M. Srivastava, G. Srinivasan, and N. G. Nanadikar, Phys. Rev. B 19, 499 (1979).

[8] G. Rado and V. Folen, J. Appl. Phys. 31, 62 (1960).

[9] P. Bercoff and H. Bertorello, J. Magn. Magn. Mater. 169, 314 (1997).

[10] K. M. Kojima, R. Kadono, M. Miyazaki, M. Hiraishi, I. Yamauchi, A. Koda, Y. Tsuchiya, H. Suzuki, and H. Kitazawa, Phys. Rev. Lett. 112, 087203 (2014).

[11] G. J. Nilsen, Y. Okamoto, T. Masuda, J. Rodriguez-Carvajal, H. Mutka, T. Hansen, and Z. Hiroi, Phys. Rev. B 91, 174435 (2015).

[12] M. Reehuis, M. Tovar, D. M. Többens, P. Pattison, A. Hoser, and B. Lake, Phys. Rev. B 91, 024407 (2015).

[13] M. S. Seehra, V. Singh, S. Thota, B. Prasad, and J. Kumar, Appl. Phys. Lett. 97, 112507 (2010); M. S. Seehra, V. Singh, and S. Thota, J. Appl. Phys. 110, 113907 (2011).

[14] P. W. Anderson, Phys. Rev. 102, 1008 (1956).

[15] S. Thota and M. S. Seehra, J. Appl. Phys. 113, 203905 (2013); 118, 129901 (2015).

[16] S. Thota, V. Narang, S. Nayak, S. Sambasivam, B. C. Choi, T. Sarkar, M. S. Andersson, R. Mathieu, and M. S. Seehra, J. Phys.: Condens. Matter 27, 166001 (2015).
[17] J. Hubsch and G. Gavoille, Phys. Rev. B 26, 3815 (1982).

[18] G. Gavoille, J. Hubsch, and S. Koutani, J. Magn. Magn. Mater. 102, 283 (1991).

[19] J. K. Srivastava, J. A. Kulkarni, S. Ramakrishnan, S. Sing, V. R. Marathe, G. Chandra, V. S. Darshane, and R. Vijayaraghavan, J. Phys. C: Solid State 20, 2139 (1987).

[20] S. Ogawa and S. Waki, J. Phys. Soc. Jpn. 20, 540 (1965).

[21] J. K. Kwak, K. H. Park, D. Y. Yun, D. U. Lee, T. W. Kim, D. I. Son, J. H. Han, and J. Y. Lee, J. Korean Phys. Soc. 57, 1803 (2010).

[22] J. G. Kim, D. L. Pugmire, D. Bhattagila, and M. A. Langell, Appl. Surf. Sci. 165, 70 (2000).

[23] S. C. Petitto, E. M. Marsh, G. A. Carson, and M. A. Langell, J. Mol. Catal. A: Chem. 281, 49 (2008).

[24] T. J. Chuang, C. R. Brundle, and D. W. Rice, Surf. Sci. 59, 413 (1976).

[25] Y. Fu, H. Du, S. Zhang, and W. Huang, Mater. Sci. Eng. A 403 , 25 (2005).

[26] E. McCafferty and J. P. Wightman, Surf. Interface Anal. 26, 549 (1998).

[27] J.-M. Themlin, M. Chtaïb, L. Henrard, P. Lambin, J. Darville, and J. M. Gilles, Phys. Rev. B 46, 2460 (1992).

[28] J. Xu, P. Gao, and S. T. Zhao, Energy Environ. Sci. 5, 5333 (2012).

[29] P. N. Shelke, Y. B. Khollam, K. R. Patil, S. D. Gunjal, S. R. Jadkar, M. G. Takwale, and K. C. Mohite, J. Nano. Electron. Phys. 3, 486 (2011).

[30] S. Ivanov, R. Tellgren, F. Porcher, G. Andre, T. Ericsson, P. Nordblad, N. Sadovskaya, G. Kaleva, E. Politova, M. Baldini, C. Sun, D. Arvanitis, P. Anil Kumar, and R. Mathieu, Mater. Chem. Phys. 158, 127 (2015).

[31] A. H. Morrish, The Physical Principles of Magnetism (WileyVCH, New York, 2001), p. 696.

[32] J. D. Rall, M. S. Seehra, and E. S. Choi, Phys. Rev. B 82, 184403 (2010); J. D. Rall and M. S. Seehra, J. Phys.: Condens. Matter 24, 076002 (2012).

[33] M. S. Seehra and V. Singh, J. Phys.: Condens. Matter 25, 356001 (2013).

[34] G. Srinivasan and M. S. Seehra, Phys. Rev. B 28, 1 (1983). 